\title{
Use of Geographic Information System Tools in Research on Neonatal Outcomes in a Maternity- School in Belo Horizonte - Brazil
}

\author{
Juliano de S. Gaspar \\ Pós-Graduação em Saúde da Mulher \\ Faculty of Medicine of UFMG \\ Belo Horizonte, Brasil \\ Zilma S. N. Reis \\ Pós-Graduação em Saúde da Mulher \\ Faculty of Medicine of UFMG \\ Belo Horizonte, Brasil \\ Marcelo S. Júnior \\ Pós-Graduação em Saúde da Mulher \\ Faculty of Medicine of UFMG \\ Belo Horizonte, Brasil
}

\author{
Thabata Sá \\ Hospital das Clínicas of UFMG \\ Belo Horizonte, Brasil
}

Renato F. N. Júnior

Faculty of Production Engineering

Universidade Salgado de Oliveira

Belo Horizonte, Brasil

Rafael R. Gusmão

Faculty of Medicine of UFMG

Belo Horizonte, Brasil

\begin{abstract}
Aim: This study proposes to evaluate the spatial distribution of the public obstetric care in the city of Belo Horizonte. It will also correlate the primary care units (PCU) with the immediate neonatal outcomes of a maternity-school of Belo Horizonte, according to risk pregnancy and obstetric outcome. Method: Descriptive geographic-spatial research. This study analyzed a cohort of 2956 newborn who received care at birth in maternity-school, Hospital das Clinicas (HC) of Federal University of Minas Gerais (UFMG) between the January/2013 to July/2014. The gestational risk, the local of primary care unit (PCU) of prenatal, immediate neonatal outcome was studied. The QGIS 2.4 open source software was used to generate thematic maps and analyses. Results: It was observed that among the $\mathbf{2 0 8 3}$ births analyzed $1154(55.4 \%)$ were classified as high risk for maternal and $634(30.4 \%)$ with poor neonatal outcome, also, that has a concentration of women living in the northwest of the city to officially refer to their childbirth mothers in the maternityschool. In cases of high risk pregnancy and perinatal complications referencing also occurs from practically all other regions of the city. Discussion: The integration of hospital clinical and administrative data with cartographic databases, through through this study, was able to make clear the patterns of referencing for childbirth in maternity-school in high risk pregnancy. Despite the limitations of a descriptive study, the analysis makes clear that the choice of place of childbirth, exceeds the matters set out in government planning of emergency obstetric referencing by sanitary districts.
\end{abstract}

Keywords-Geographic Information Systems (GIS); Fetal Malformation; Health Indicators; Obstetrics Result; Primary Care Unit (PCU); Public Health

\section{INTRODUCTION}

The decentralization of healthcare through regional and hierarchical connected health services, while sustaining the management of care in a primary level are guidelines from the Brazilian Heath System(SUS) [1]. In the obstetric context, even though the labor occurs in a hospital environment, its success must be seen as a final process initiated in the primary care. The gestation wellness initiate with a correct family planning, involves preconception evaluation, passes through an early and effective prenatal assistance and, undeniably, through proper parturitions conditions. All these steps depend on an accessible and well-scaled health care network with quality $[2,3]$.

About 2.9 million annual births are estimated in the country. Among these, there are deaths of approximately 10.6 in every 1000 conceptuses in the neonatal period and 64.8 women in each 100 thousand live births, this according to data from the year 2011 [4]. These are mostly considered preventable deaths [5]. Such maternal and child indicators are still far behind the desired expectations and are reflections of the level of economic development, culture and technology of the country, and the current difficulties of prenatal and delivery care in our health services $[6,7]$.

Efforts have been undertaken in the sense of better understand the mechanisms that lead to poor maternal and neonatal results. These will be studied in a special manner as to high-risk pregnancy, and systematized care for pregnant women in labor [8]. 


\section{A. Geographical Information Systems}

The geography plays a key role in almost every decision are made. The choice of locations, the point of market segments, planning distribution networks, responding to emergencies, or redrawing the limits of countries, all of these problems involve questions of geography. The spatial characteristics, such as topography and geographical dispersion of the population, are factors in determining equitable distribution of resources [9].

The Geographic Information Systems (GIS) provide related data from a spatial context and their respective placements. This technology allows, in a simple way, to visualize data with different degrees of complexity on a map. This often provides a useful way to reveal spatial and temporal relations between data. Combining data and applying some analytic rules, it is possible to create a pattern in order to help answer the question previously asked [10]

Researchers, and public health professionals responsible for setting policy, and others can use GIS to better understand geographic relationships. These relationships affect health outcomes, risks to public health, transmission of disease, access to health care and other public health concerns [11].

Many are simple and functional GIS to explore the distances between health resources and population, bringing great benefits. Thus, questions such as: How far is the nearest hospital for a population, or where is the nearest institution for blood donation, can be easily answered avoiding embarrassment.

The georeferenced displacement of women seeking obstetric care constitutes an important source of data on quality of care. Information about pregnancy and childbirth are important in assessing the quality of this assistance as well as provide efficient mechanisms for continuous monitoring of performance. This approach, coupled with the reality, lies in the movement patterns that may allow health professionals and managers to monitor the quality, and the course of actions for improvement of care. This will contribute to the targeting strategies that are necessary to improve mother and child health indicators [12].

\section{B. Aim}

This study proposes to evaluate the spatial distribution of the public obstetric care in the city of Belo Horizonte. It will also correlate the primary care units (PCU) with the immediate neonatal outcomes of a maternity-school of Belo Horizonte, according to risk pregnancy and obstetric outcome.

\section{METHODS}

\section{A. Study design}

Descriptive geographic-spatial research. This study analyzes a cohort of 2956 newborn who received care at birth in maternity-school, Hospital das Clinicas (HC) of Federal University of Minas Gerais (UFMG) between the January/2013 to July/2014.

\section{B. Variables}

A system of obstetric information (SISMater®) [13] in which data such as gestational risk classification according to the SUS criteria[8], the local of primary care unit (PCU) of prenatal, immediate neonatal outcome of interest were extracted.

Perinatal death, fifth minute Apgar score less than seven, birth weight $<2500 \mathrm{~g}$, premature delivery (less than 32 weeks) or requiring admission to the neonatal unit were grouped as poor neonatal outcome.

Data from the Municipal Department of Health of Belo Horizonte (SMSA-BH) (SM-Saúde-BH, 2014): the amount of maternity and PCU (Primary Care Units) existing in the city, their respective addresses. Furthermore, the service capacity of each PCU was estimated from the amount of family health teams. The data refers to the year 2014 and defines the offer of public obstetric care in the city, including seven maternities and 148 PCU.

\section{GIS Software}

The QGIS 2.4 open source software was used to generate thematic maps. Maternities, PCU and place of residence of the women were geographically mapped using the official cartographic design of the city of Belo Horizonte.

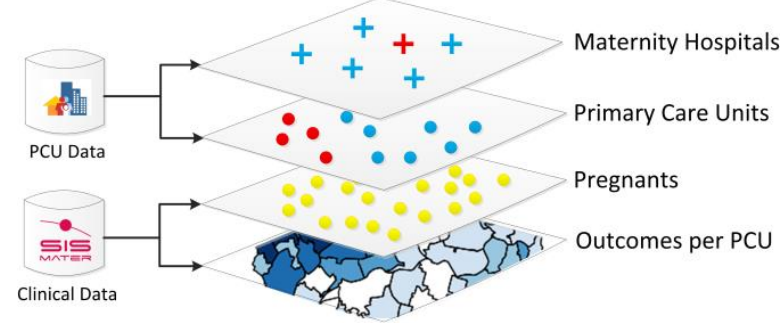

Fig. 1. GIS layers defined Legend: PCU - Primary Care Unit

Independent layers were designed with the specific features selected in this analysis, as well as those with maternal and neonatal outcomes (Fig 1).

\section{Ethical aspects}

The present study was approved by the Ethics Committee for Research of the UFMG under the registration number (Brazil Platform: CAE 0550.4612.9.0000.5149) all human research principles were respected. The proposition was presented and supported by the Hospital das Clinicas of the UFMG and Health Informatics Center of the Medicine School, UFMG.

\section{RESULTS}

\section{A. Data Quality Analysis}

Official Data, referring to the year 2010, indicates a prenatal coverage of $98.9 \%$, where $99.7 \%$ of the 31.147 annual births were performed in hospitals [14]. In this period occurred a total of 2956 births in the Hospital das Clinicas. Of these, $366(12.4 \%)$ were excluded from this study because they were women living in other cities. This certainly evidentiates the role of this unit as a reference for delivery in this community. Seventy eight (78) records with women made their prenatal assistance in private network, 397 records without the indication of the PCU in who carried out the pre- 
natal and 32 records that women who did not have prenatal assistance, were also excluded (Table 1).

TABLE I. DATA QUALITY ANALISES

\begin{tabular}{lrr}
\hline Data description & N & \% \\
\hline Prenatal in maternity-school from HC & 1113 & 37.7 \\
Prenatal from PCU in the city & 970 & 32.8 \\
Without prenatal information & 397 & 13.4 \\
Prenatal realized in other city & 366 & 12.4 \\
Prenatal realized in private network & 78 & 2.6 \\
Without prenatal & 32 & 1.1 \\
\hline Total & $\mathbf{2 9 5 6}$ & $\mathbf{1 0 0 . 0}$ \\
\hline
\end{tabular}

\section{B. Patient Health}

The city has about 2.67 million people [14]. The spatial distribution of public obstetric care was plotted (Fig. 2). It is composed of 148 PCU (Fig. 3), seven maternities, amply distributed throughout the city. In this figure the influence area of maternity-school of Hospital das Clinicas was highlighted in red.

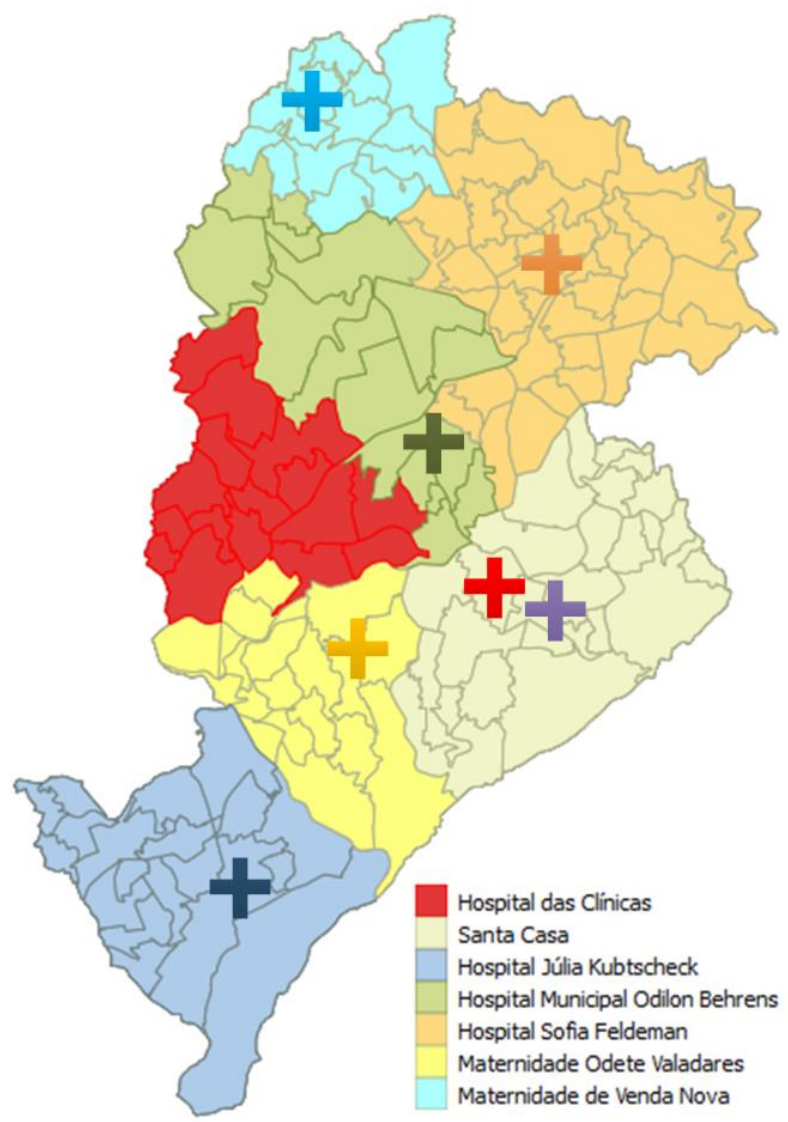

Fig. 2. Maternity Units and PCU influence area

Among the 2083 births analyzed 1154 (55.4\%) were classified as high risk for maternal and/or neonatal complications. As for the place of the prenatal care, only 1113 (53.4\%) made up in your own university service.

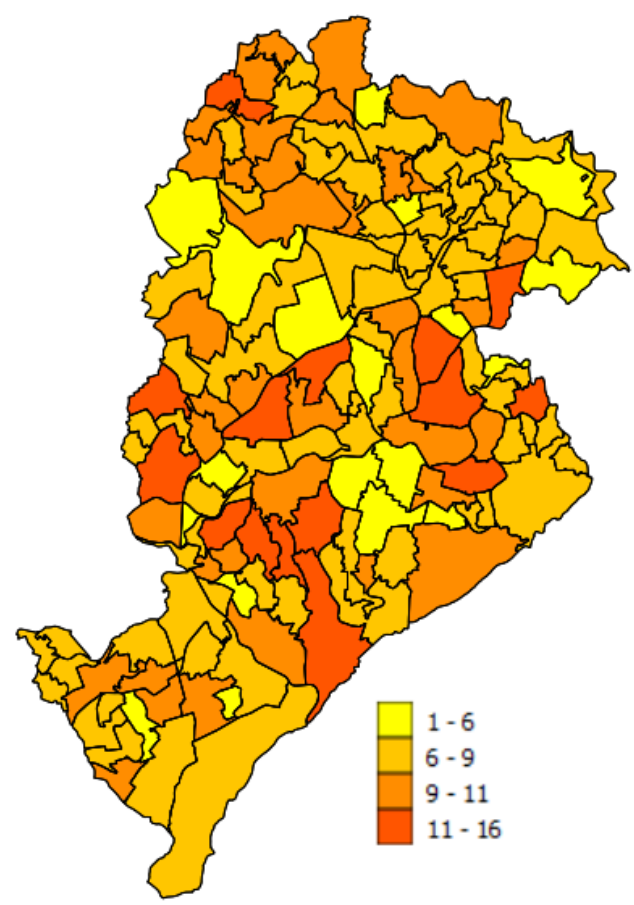

Fig. 3. Primary Care Unit (PCU) distribution by the size of potential service (number of profesionals)

The spatial relationships between the place of PCU where the mothers made the prenatal of the 2083 newborns in this city, were presented in Fig. 4.

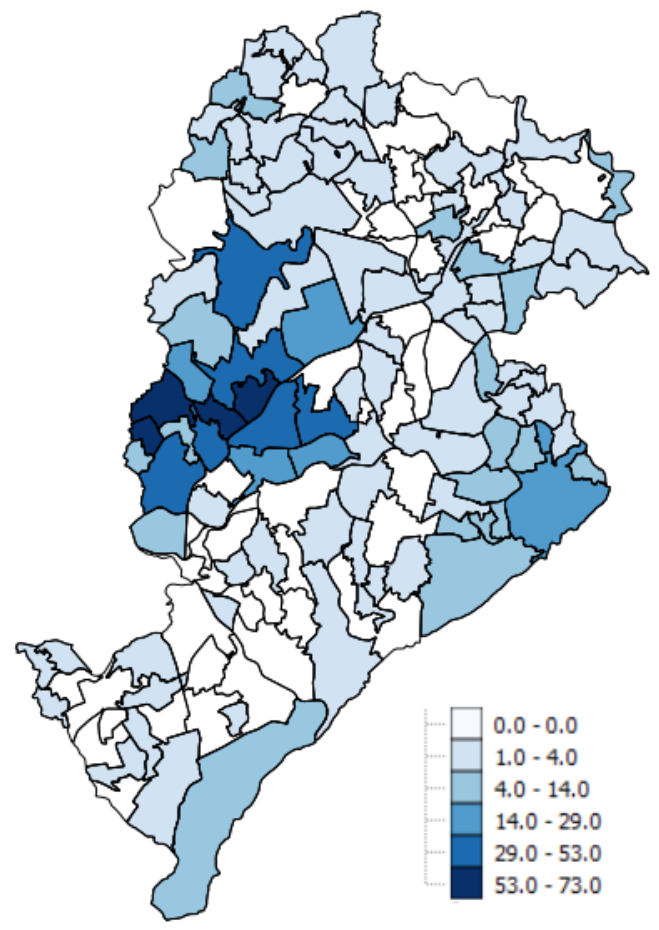

Fig. 4. Distribution of births with prenatal performed on PCU of women that had assistance in maternity-school, UFMG

There was a concentration in the northwest region of the city, because it focuses where the PCU that officially reference their patient to births in the motherhood studied. 
Among the 363 births with low weight at birth $(<2500 \mathrm{~g})$ and 237 premature newborns. In Table 2 are summarized neonatal outcome of births evaluated.

TABLE II. NEONATAL OUTCOME IN MATERNITY OF HOSPITAL DAS CLINICAS, UFMG (N=2083)

\begin{tabular}{lrr}
\hline Poor neonatal outcome caracteristics & N & \% \\
\hline Low weight at birth $(<2500 \mathrm{~g})$ & 363 & 17.4 \\
ICU neonatal stay & 360 & 17.2 \\
Premature delivery & 237 & 11.3 \\
Apgar $<7$ (5o minute) & 115 & 5.5 \\
\hline Poor neonatal outcome & $\mathbf{6 3 4}$ &
\end{tabular}

However, note that this also gives referencing from practically all other regions of the city, especially for pregnancies at high risk for maternal and neonatal morbidities (Fig. 5).

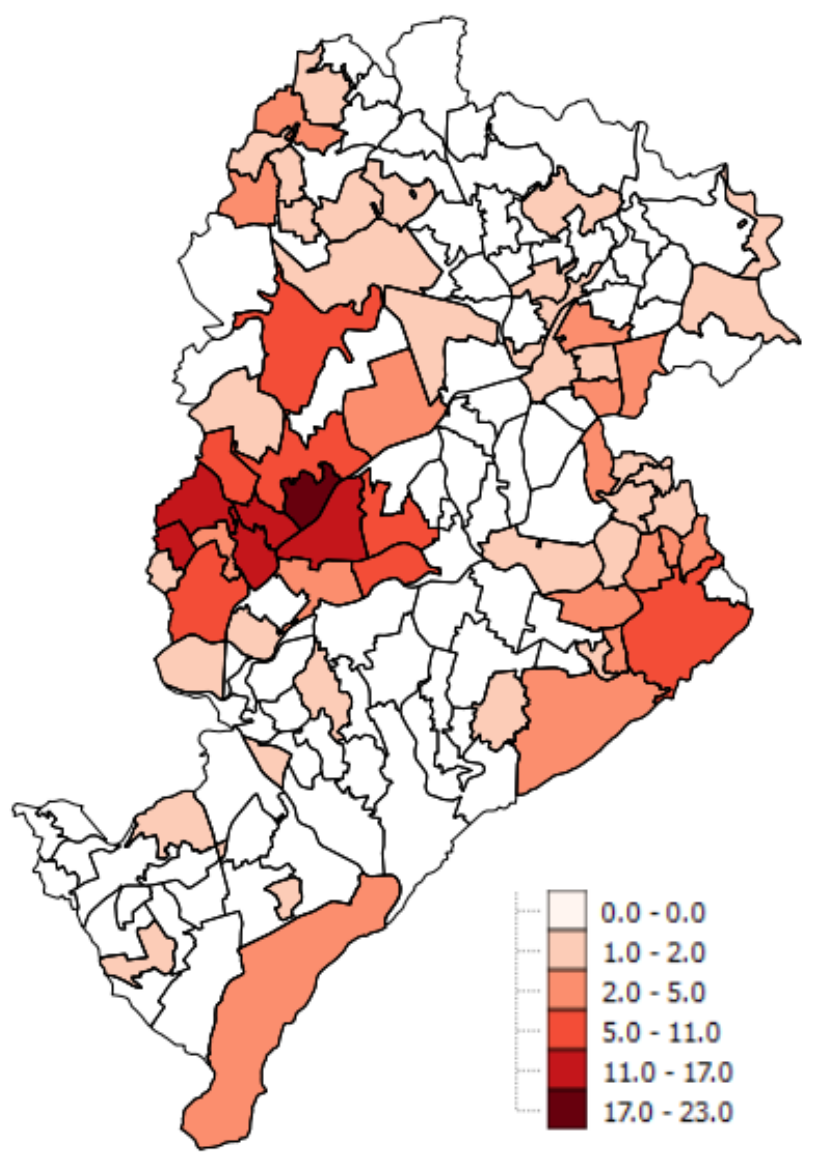

Fig. 5. Spatial distribution of gestational risk of women that had assistance in maternity-school, UFMG by PCU

About a quarter of the analyzed population had some type of neonatal complications. The spatial distribution of poor neonatal outcome (Fig. 6) takes place throughout the city, with some areas of concentration. One is the Northwest region itself, considered coverage for maternity-school. Others to the north, in the surroundings of large public hospitals also assisting childbirth. Noteworthy is the large number of women from Eastern region and the territorial limits of the city to the North, East and Northwest.

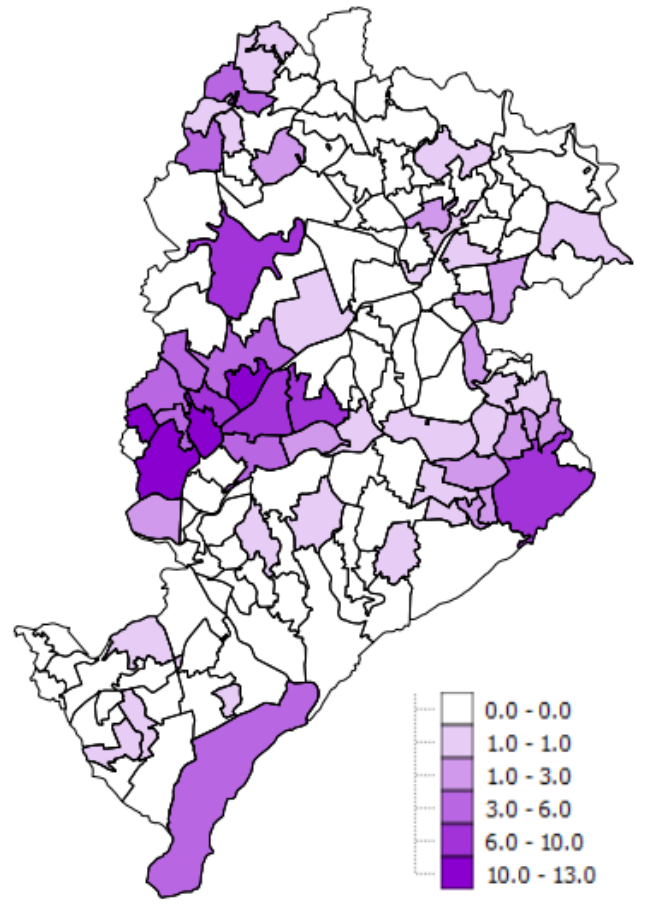

Fig. 6. Spatial distribution of poor neonatal outcome of women that had assistance in maternity-school, UFMG

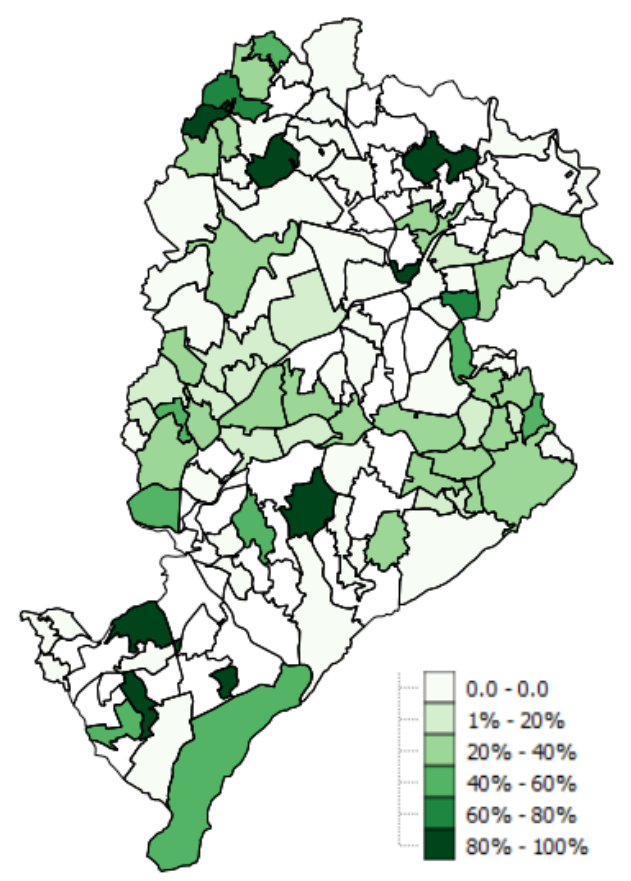

Fig. 7. Percentage distribution of births with poor neonatal outcome by PCU of women that had assistance in maternity-school, UFMG by PCU

The percentage distribution of births with poor neonatal outcome and the spatial relationships between the places of PCU where the mothers made the prenatal were plotted in Figure 7. It is relevant to highlight the lesser importance of maternity-school as a reference for women living in the Southcentral region. In these places there is also a smaller supply of public health services, coincident with its feature of 
commercial and high socioeconomic standard. The surroundings of maternity-school, called the Health Campus, is the site of a high concentration of health facilities providing care in the private sector.

\section{DISCUSSION}

The form of spatial organization of the provision of health services in this city is managed by the local public administration. This reflects the structure of the levels of assistance for health care, as in the model of the Family Health Program, being implemented in Brazil since 1992 [15, 16]. The city is divided into nine sanitary disctricts corresponding to the regional administration units and the administrativewelfare organization of the public health service [17]. At Northwest Health District are 10 of the 12 PCU that reference pregnant women priority for maternity-school. This analysis confirms the role of this service as an important center for emergency obstetric care for women living in this region.

Conversely, women with high-risk pregnancies indistinctly come from all nine sanitaries disctricts. Many of the highly complex features offered by this university reference center are unique to the state of Minas Gerais, such as Fetal Medicine care. There is a significant prevalence of fetal anomalies focused on childbirth in this unit, reaching $9.6 \%$ of births and high-risk obstetrical cases in general [13]. Other studies show that in Brazil, there are many serious pregnancy complications during childbirth. These are associated with nearmiss and maternal death, as hemorrhage, sepsis, and obstructed labor. Their prognosis is defined by technological resources and quality of services offered by tertiary and quaternary hospitals [18] . This justifies our findings in clear demand for quality care in high risk situations. Even living within close proximity to other public hospitals, many women sought the solution of health issues of high complexity in the maternity-school, rather than a larger displacement.

One of the aims of this study is the quest for recognition and analysis of geographic and logistical access routes for women with high gestational risk cases. Also to identify the resources of an appropriate tertiary and quaternary care unit complex, where public risk is. By mapping geographically the maternity-school and the origin of the displacements of the most serious perinatal cases in search of this service, found influence of university service throughout the country. This also serves women living in other nearby cities [13], but it was not the object of this study.

A limitation of this approach is the absence of markers of socioeconomic disadvantages and population density between the layers used in the maps. Certainly the future exploration of spatial relationships of these factors with the obstetric outcome will still result in relevant information. However, this is an unprecedented review on this community and context. It makes clear the potential of integration between hospital and government information for understanding the obstetric outcomes through georeferencing techniques. It is known that the accessibility to health services may be an important outcome of reorganizing care to pregnant women and newborns. A study conducted in the city of Recife (Brazil) showed that proximity of residence or work has been the most important element in choosing the health unit for performing prenatal care [19]. In the case of Belo Horizonte, the reasons for displacement exceeded the logic of proximity access or even municipal planning referencing of obstetric emergencies. It also reflected the search for technological resources and expertise of a university hospital to offer a better approach to risk cases.

The guarantee of care by level of attention and its timely access from a rating of adequate risk pregnancy, and a system of referencing and transportation to mother and child, are fundamental effective strategies. These seek reduction of maternal and neonatal morbidity or mortality $[1,20]$. Expected to have contributed to a model of analysis that can support more effective strategies for maternal and child care.

\section{CONCLUSION}

The integration of clinical and administrative data with cartographic base of the city, through this study, was able to make clear the patterns of referencing for childbirth in maternity-school in high risk pregnancy. Despite the limitations of a descriptive study the analysis makes clear that the choice of place of childbirth exceeds the matters set out in government planning of emergency obstetric referencing by sanitary districts.

\section{ACKNOWLEDGMENT}

The researchers acknowledge the support given by the Perinatal Commission of Belo Horizonte.

\section{REFERENCES}

[1] Victora Cg Fau - Aquino, E.M.L., et al., Maternal and child health in Brazil: progress and challenges. The Lancet. 377(9780): p. 1863-1876. 2001

[2] Brasil, M.d. Saúde, and D.d.A.P. Estratégicas, Política Nacional de Atenção Integral à Saúde da Mulher Princípios e Diretrizes, M.d. Saúde, Editor Ministério da Saúde: Brasília. p. 82. 2007.

[3] Brasil and M.d. Saúde, Manual dos comitês de prevenção do óbito infantil e fetal, in Normas e Manuais Técnicos, M.d. Saúde, Editor Ministério da Saúde do Brasil: Brasília. 2004.

[4] MS-Brazil. DATASUS: Sistema de Informação em Saúde do SUS. 2014 13/01/2014]; Available from: http://www2.datasus.gov.br/DATASUS.

[5] Brasil, Manual dos comitês de mortalidade materna, S.d.A.à. Saúde, Editor: Brasília. p. 104. 2007.

[6] Reis, Z.S.N., et al., Análise de indicadores da saúde materno-infantil: paralelos entre Portugal e Brasil. Revista Brasileira de Ginecologia e Obstetrícia. 33: p. 234-239. 2011.

[7] MS-Brasil. Gestantes receberão auxílio financeiro para deslocamento. 2012 3/8/2012 [cited 2014 13/01/2014]; Available from: http://dab.saude.gov.br/portaldab/noticias.php?conteudo=_\&cod=1486.

[8] MS-Brasil, Gestação de Alto Risco: Manual Técncio. Secretaria de Atenção à Saúde: Departamento de Ações Programáticas Estratégicas., Ministério da Saúde do Brasil: Brasília. p. 302. 2010.

[9] Leitner, H., et al., Models for making GIS available to community organizations: dimensions of difference and appropriateness. In Community Participation and Geographic Information Systems: p. 3752. 2002.

[10] Maged, N. and B. Kamel, Towards evidence-based, GIS-driven national spatial health information infrastructure and surveillance services in the United Kingdom. 2004.

[11] CDC. Centers for Disease Control and Prevention. 2013 [cited 2013 23/10/2013]; Available from: http://www.cdc.gov/.

[12] MS-Brasil, Política Nacional de Atenção Integral à Saúde da Mulher Princípios e Diretrizes. Ministério da Saúde: Secretaria de Atenção à Saúde Departamento de Ações Programáticas Estratégicas. Série C. Projetos, Programas e Relatórios (1 ed). 2009. 
[13] Gaspar, J., et al., Maternal and Neonatal Healthcare Information System: Development of an Obstetric Electronic Health Record and Healthcare Indicators Dashboard, in Information Technology in Bio- and Medical Informatics, M. Bursa, S. Khuri, and M.E. Renda, Editors. Springer Berlin Heidelberg. p. 62-76. 2013.

[14] Beale, T. and S. Heard, openEHR Architecture-Architecture Overview, 2008. 2010

[15] Victora, C.G., et al., Health conditions and health-policy innovations in Brazil: the way forward. The Lancet. 377(9782): p. 2042-2053. 2011.

[16] Paim, J., et al., The Brazilian health system: history, advances, and challenges. The Lancet. 377(9779): p. 1778-1797. 2011.
[17] SM-Saúde-BH. Áreas de Abrangência dos Centros de Saúde. 2014 [cited 2014; Available from: http://gestaocompartilhada.pbh.gov.br/estrutura-territorial/areas-deabrangencia-dos-centros-de-saude.

[18] Beale, T., et al., OpenEHR architecture overview. The OpenEHR Foundation. 2006.

[19] Kalra, D., Electronic health record standards. Yearb Med Inform: p. 136-144. 2006.

[20] MS-Brasil, Portaria $N^{\circ} 1.459,24 / 06 / 2011$ - Institui, no âmbito do Sistema Único de Saúde - SUS - a Rede Cegonha., M.d.S.d. Brasil, Editor Ministério da Saúde: Brasília. 2011. 